\title{
Early aseptic loosening of cementless monoblock acetabular components
}

\section{Miettinen, Simo S. A.}

2017-04

Miettinen , S S A , Makinen , T J , Laaksonen , I, Mäkelä , K, Huhtala , H , Kettunen , J \&

Remes, V 2017 , ' Early aseptic loosening of cementless monoblock acetabular components

' , International Orthopaedics, vol. 41 , no. 4 , pp. 715-722 . https://doi.org/10.1007/s00264-016-3254-8

http://hdl.handle.net/10138/236754

https://doi.org/10.1007/s00264-016-3254-8

publishedVersion

Downloaded from Helda, University of Helsinki institutional repository.

This is an electronic reprint of the original article.

This reprint may differ from the original in pagination and typographic detail.

Please cite the original version. 


\title{
Early aseptic loosening of cementless monoblock acetabular components
}

\author{
Simo S. A. Miettinen ${ }^{1}$ - Tatu J. Mäkinen ${ }^{2} \cdot$ Inari Laaksonen $^{3} \cdot$ Keijo Mäkelä $^{3}$ • \\ Heini Huhtala ${ }^{4}$ • Jukka Kettunen ${ }^{1}$ • Ville Remes ${ }^{2,5}$
}

Received: 30 January 2016 / Accepted: 19 July 2016 / Published online: 10 August 2016

(C) SICOT aisbl 2016

\begin{abstract}
Purpose Early aseptic loosening of cementless monoblock acetabular components is a rare complication of total hip arthroplasty (THA) and hip resurfacing arthroplasty (HRA). The purpose of this study was to evaluate the incidence and risk factors for early aseptic loosening of the cementless monoblock acetabular components.

Methods This retrospective analysis consisted of 4,043 cementless hip devices (3,209 THAs and 834 HRAs). We identified 41 patients with early aseptic loosening of the acetabular component. A control group of 123 patients without acetabular component loosening was randomly selected. The demographic data and risk factors for loosening of the acetabular component were evaluated. The mean follow-up time was 4.6 years (range, 1.7-7.8). The end-point was acetabular revision.

Results The incidence of early acetabular component loosening was $1.0 \%$. Mean time to revision was 1.2 years (SD 1.6,
\end{abstract}

Electronic supplementary material The online version of this article (doi:10.1007/s00264-016-3254-8) contains supplementary material, which is available to authorized users.

Tatu J. Mäkinen

tatu.makinen@hus.fi

1 Department of Orthopaedics, Traumatology and Hand Surgery, Kuopio University Hospital, Kuopio, Finland

2 Department of Orthopaedics and Traumatology, Helsinki University Hospital and University of Helsinki, Sairaalakatu 1, 01400 Vantaa, Finland

3 Department of Orthopaedics and Traumatology, Turku University Central Hospital, Turku, Finland

4 School of Health Sciences, University of Tampere, Tampere, Finland

5 Pihlajalinna Oy, Helsinki, Finland range $0.0-5.4$ ). There was significantly more Dorr type A and $\mathrm{C}$ acetabular morphology in patients with early loosening $(P=0.014)$. The loosened components were implanted to more vertical $(P<0.001)$ and less anteverted $(P=0.001)$ position than those of the control group. Presence of acetabular dysplasia or acetabular component type did not associate to early loosening.

Conclusions Acetabular morphology (Dorr type A and C) and component positioning vertically and less anteverted were more common in patients with early aseptic loosening of cementless acetabular components. Suboptimal cup position most likely reflects challenges to obtain sufficient stability during surgery. We hypothesize that errors in surgical technique are the main reason for early loosening of monoblock acetabular components.

Keywords Acetabular morphology · Aseptic loosening · Case-control study $\cdot$ Cup positioning $\cdot$ Hip arthroplasty

\section{Introduction}

The cementless hemispherical acetabular component requires good initial fixation to allow bony ingrowth to occur. The initial press-fit is typically achieved by underreaming the acetabulum or by using non-hemispherical (flanged) components. Compared to modular acetabular components, the suggested benefits of the monoblock components used in largehead total hip arthroplasty (THA) and hip resurfacing arthroplasty (HRA) are that they allow the use of a large diameter head that may reduce the risk of dislocation and provide better biomechanics of the hip joint [1]. However, monoblock components do not allow supplementary screw fixation. Another drawback with monoblock components is the difficulty in assessing whether the component is fully 
seated to the acetabulum as the bone bed cannot be visualized through holes in the component.

Aseptic loosening of the hemispherical acetabular components was recently shown to be one of the leading causes of early failure of primary THA $[2,3]$. Various factors such as bone quality, female gender and geometry of the acetabulum have been postulated as factors influencing primary fixation of the cementless acetabular component [3-6]. In addition, underlying systemic diseases like rheumatoid arthritis and osteoporosis affect the properties of bone and also influence implant osseointegration. From a mechanical point of view, acetabular component malpositioning or failure to restore the centre of rotation of the hip joint may lead to impingement and increased edge-loading, which may lead to early loosening of the acetabular component [7]. Further studies are needed to explore patient-related and surgery-related factors associated with early acetabular component loosening.

The aim of the present study was to evaluate possible denominators related to early aseptic loosening of the hemispherical monoblock acetabular components. Specifically, patient-related factors (age, gender, pre-operative diagnosis, systemic diseases affecting bone quality), the morphology of the acetabulum (e.g. center-edge angle, acetabulum depth ratio, femoral head extrusion index, centre of hip rotation, Crowe classification) and component position (anteversion and inclination) were assessed.

\section{Patients and methods}

\section{Patients}

This retrospective case-control study was approved by the ethical review committee of the University of Turku (ETMK: 78/1801/2013). A total of 4,043 THAs and HRAs with metal-on-metal bearing surface were operated between January 2004 and December 2009 in three university hospitals. These patients formed the study population, which consisted of 3,209 THAs in 2,912 patients and 834 HRAs in 757 patients. None of the patients were excluded. Pre- and post-operative radiographs were available from all patients for the analysis.

There were 30/41 (73.2 \%) THAs and 11/41 (26.8\%) HRAs in the acetabular component loosening group (Appendix 1). Patient demographic data in terms of age, gender, underlying systemic diseases (prior diagnosis of osteoporosis, or rheumatoid arthritis or other inflammatory joint disease), co-morbidities affecting bone quality (alcohol abuse, long-term peroral corticosteroid use) and indication for surgery were collected from the medical records. We excluded patients with infection as a primary cause for component loosening from further analysis, as the study was more focused on anatomical and patient-related risk factors. Intra-operative complications were also evaluated in order to assess their effect on early acetabular component loosening.

A control group was formed by randomly selecting THAs and HRAs among 3,997 arthroplasties without acetabular component loosening. The control patients were stratified per hospital. The control group was formed randomly with a ratio of 1:3 ( 1 case : 3 controls). The similarity of the control group was compared to the patient pool of 3,879 arthroplasties without acetabular component loosening by comparing age, gender, THA and HRA components and follow-up time between the groups, and there were no statistically significant differences in these factors (Appendix 2). Furthermore, subgroup analyses were performed to compare the THAs and HRAs to control patients.

\section{Radiological analysis}

Radiological analyses were performed on plain radiographs taken before surgery and at the three month follow-up visit. In the cases where acetabular component loosening occurred before the follow-up visit, the immediate post-operative radiographs were used for analysis.

The radiographic teardrop in antero-posterior view was a landmark for many measurements used in this study [8]. The inter-teardrop-line was used as the transverse axis of the pelvis. Various radiographic measurements have been used to assess hip dysplasia at skeletal maturity [8]. For this study, we selected the following parameters for further analysis: Crowe classification, the centre-edge angle (CE), Sharp's angle, the acetabular depth-width ratio (ADR), the femoral head extrusion index (FHEI) and the anatomic hip centre measurement [10-15] (Figs. 1, 2 and 3).

The Crowe classification was used to define developmental hip dysplasia (DDH) [9]. Crowe type I has $<50 \%$ subluxation, type II has between $50 \%$ and $74 \%$ subluxation, type III has between $75 \%$ and $99 \%$ subluxation and type IV has a complete dislocation [9].

The $\mathrm{CE}$ angle of Wiberg was measured [10]. A CE angle $<$ 20 degrees indicates hip dysplasia and $>25$ degrees indicates a normal hip [10]. The angle of inclination of the acetabulum (Sharp's angle) was measured [11]. The normal range of Sharp's angle is 33-38 degrees [11]. The ADR was measured along a line running perpendicularly from the width line to the deepest point of the medial arch [12]. For the ADR the mean cut-off values are 0.235 for males and 0.233 for females [11]. The FHEI was measured to assess the degree of femoral head lateralization over the acetabular edge [13]. The normal range of the FHEI was originally $70-100 \%$ but a cut-off value of $75 \%$ was subsequently proposed $[12,13]$. The anatomic hip centre was located from the pre- and postoperative radiographs using a method described by Fessy et al. [14], which has been shown to be the most precise method for determination of the anatomic centre [8]. 


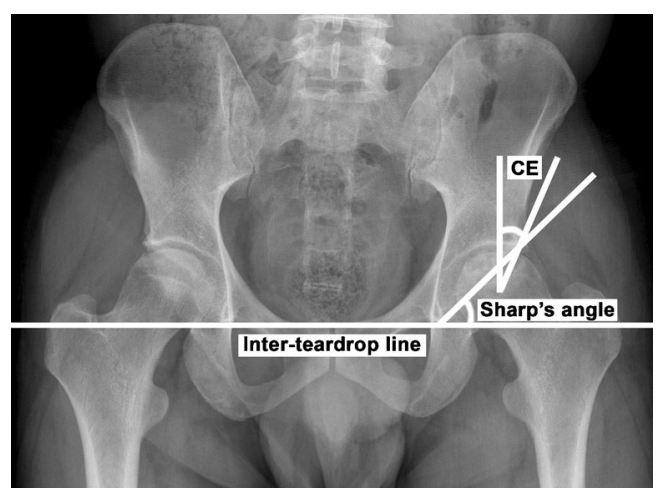

Fig. 1 The centre-edge (CE) angle is formed by a vertical line through the centre of the femoral head and perpendicular to the transverse axis of the pelvis. Sharp's angle describes the angle formed between the interteardrop line and the line connecting the inferior tip of the teardrop to the acetabular rim

The functional structure of the acetabulum changes due to osteoarthritis. It has been reported that the fixation of the cementless acetabular component is related to the bone structure of the acetabulum [4]. We classified acetabula into three types (type A, type B and type C) based on their acetabulum roof morphology on plain pre-operative radiographs according to Dorr [4]. Type A acetabulum has an isosceles triangle with equal medial and lateral walls or beams and a shorter base. Type B has an extended triangle, which has a pseudopod that extends into the teardrop and creates a thick medial wall. Type $\mathrm{C}$ is found only in dysplastic hips and has a right-angle triangle with a straight lateral wall. The femoral head may or may not be located under the triangle [4].

Acetabular component inclination and anteversion angles were measured from the post-operative radiographs. The inclination angle of the acetabulum component was measured according to the method described by Widmer [15]. Anteversion was measured according to the method described by Murray [16]. A true-lateral radiograph was used to measure the anteversion although a previous study showed that

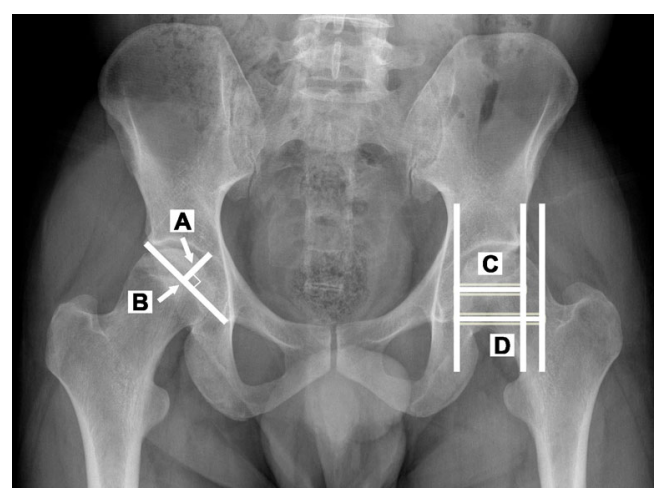

Fig. 2 The acetabular depth-width ratio (ADR) is the depth of the acetabulum (a) divided by the width of the acetabulum (b). The femoral head index (FHEI) quantifies how much of the femoral head is covered by the acetabulum $(\mathrm{C} / \mathrm{D} \times 100)$

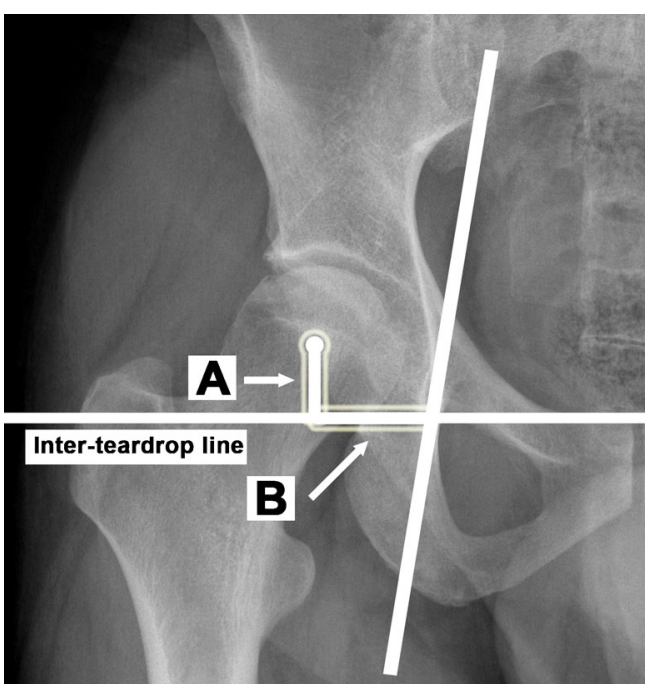

Fig. 3 Horizontal (b) distance of the hip joint centre is measured from the intersection of the distal end of the inter-teardrop line and from the line between the inferior edge of the sacroiliac joint and teardrop. The vertical (a) distance of the hip joint centre is measured between the centre of the femoral head and perpendicular to the inter-teardrop line

acetabular component anteversion could be accurately measured with a single pelvic radiograph [17].

The acetabulum components were divided into four groups based on the amount of containment of the cup described by Sarmiento et al. [18]. Containment was measured from the post-operative radiographs. Containment by bone was recorded as (i) $100 \%$, (ii) $90-99 \%$, (iii) $75-99 \%$ and (iv) $<75 \%$.

Radiolucent gaps on the initial post-operative radiograph and radiolucent lines or osteolysis at the bone component interface on the subsequent radiographs were recorded as described by DeLee and Charnley [19].

Picture archiving and communication systems (PACS) were used in every participating hospital. Measurements were made using tools provided by Agfa IMPAX (ver. 6.5.2.657) and Sectra Workstation IDS7 (ver. 15.1.8.5).

\section{Intra- and inter-observer error}

Measurements were re-analyzed after 2 months by the same observer (S.M.) to determine intra-observer error and by another observer (J.K.) to determine inter-observer agreement, and also the reliability of observers was evaluated with parallel test.

\section{Statistical analysis}

For continuous variables, comparisons between calcar fracture and control group were done using Mann-Whitney U-test. For categorical variables, Pearson's chi-square test was used. Fisher's exact test was used to analyze differences in operative diagnosis and radiographic measurements between the groups. Bland-Altman comparison analysis was used to determine the intra- and inter-observer agreement and Pitman's test 
of difference was performed to study intra- and inter-observer reliability. Two-tailed $P$ values are reported and $P<0.05$ was considered statistically significant. All data were analyzed statistically using SPSS (SPSS Inc., Chicago, IL, USA. Ver 21.0.0, IBM).

\section{Results}

There were a total of $41 / 4043$ cases of early acetabular component loosening (1.0\%). There were 30/3209 (0.9\%) cases of early acetabular component loosening in the conventional THA group and $11 / 834(1.3 \%)$ in the HRA group $(P=0.32)$. No differences in the rate of acetabular loosening were found between the participating hospitals $(0.6-1.4 \%, P=0.07)$. In the subgroup analysis, there were no significant differences in the demographic data in THAs or HRAs (Appendix 3).

Mean time to revision due to early acetabular component loosening was 1.2 years (range, 1 day-5.4 years) and 31/41 $(75.6 \%)$ of the cases of acetabular component loosening occurred within two years post-operatively. In addition, 9/41 $(21.9 \%)$ of the acetabular component loosenings occurred within five days post-operatively.

There was no statistically significant difference in acetabulum component types in the THA $(P=0.08)$ and in the HRA group $(P=0.1)$ (Appendix 1). There were more periprosthetic fractures in the control group $(P=0.01)$, otherwise there were no statistically significant differences between groups in demographic data (Table 1).

Pre-operative radiographic measurements showed that the mean CE and Sharp angles, neck-shaft angle, FHEI and ADR of both groups were within the normal limits and there also were no statistically significant differences between the groups (Table 2). Before surgery, there were no differences in the horizontal or vertical position of the hip centre of rotation. However, post-operatively the vertical hip centre of rotation was located more cranially in the acetabular component loosening group as compared to the control group $(P=0.001)$.

There was no statistically significant difference between the groups in Crowe classification of the DDH. Interestingly, there were significantly more Dorr type A and type C acetabular morphology in the acetabular component loosening group as compared to the control group $(P=0.01)$ (Table 2). However, the subgroup analysis showed that Dorr type A and type $\mathrm{C}$ morphologies were in the THA group but not in the HRA group (Appendix 4). Post-operative radiographic measurements found no differences between groups either in cup containment or appearance of radiolucent lines (Table 2). However, the acetabular components were implanted in a more vertical position in patients with loosening as compared to the controls, but this association was observed only in the THA subgroup (Appendix 4). Also the loosened components were less anteverted.

\section{Intra- and inter-observer error}

The mean difference between intra-observer measurements ranged from 1.7 to $2.4 \mathrm{~mm}(95 \% \mathrm{CI}-0.6$ to 5.4$)$ and the mean difference in measured angles ranged from $-5.4^{\circ}$ to $5.1^{\circ}\left(95 \% \mathrm{CI}-14.1^{\circ}\right.$ to $\left.11.2^{\circ}\right)$. The mean difference between inter-observer measurements ranged from 0.5 to $3.0 \mathrm{~mm}$ (95\% CI -2.2 to 7.4 ) and the mean difference in measured angles ranged from $-3.3^{\circ}$ to $6.1^{\circ}\left(95 \% \mathrm{CI}-8.7^{\circ}\right.$ to $\left.10.7^{\circ}\right)$. Pitman's test revealed that there were no significant differences in intra-observer measurements $(P>0.05)$. There was a significant difference in only one inter-observer measurement (acetabulum width; $P=0.03$ ). None of the other interobserver measurements differed significantly from the original measurements according to Pitman's test $(P>0.05)$.

\section{Discussion}

The use of cementless acetabular components has gained popularity over the past decade despite the fact that several publications show inferior survivorship compared to cemented acetabular components $[5,20,21]$. The reasons for the increased use of cementless acetabular components are their straightforward implantation, the ability to adjust component position and the variety of bearing and liner options. Loosening of the acetabular component is the most common reason for revision in cementless metal-on-metal THAs [3]. Cementless THA revision typically occurs during early follow-up. In a recent study of 80 metal-on-metal hips that underwent acetabular revision, $92.5 \%$ of revisions were performed within three years after the index surgery [3]. Aseptic loosening of a cementless hemispherical acetabular component has been reported as one of the leading modes of early failure $[2,3]$. The morphology of the acetabulum, comorbidities affecting bone quality and errors in surgical technique have been postulated to affect the osseointegration of the cementless component [4].

In our study, there was significantly more Dorr type A and $\mathrm{C}$ acetabular morphology in patients with early acetabular component loosening. The loosened components were implanted to more vertical and less anteverted position. Radiological parameters representing hip dysplasia did not show significant association with early acetabular component loosening. It is most likely that the majority of early loosening is related to failure of initial fixation leading to insufficient osseointegration of the component. If there is uncertainty about initial press-fit of the monoblock component, modular cementless cups with screws, or cemented acetabular cups should be used [22]; a previous study even showed that there is no difference in component survival if a component with or without screw fixation is used [23]. 
Table 1 Patient demographics and details of surgery

\begin{tabular}{|c|c|c|c|}
\hline Demographic & $\begin{array}{l}\text { Acetabular component } \\
\text { loosening group }\end{array}$ & Control group & $P$-value \\
\hline Age, years & $59.2(12.6,27.9-90.8)$ & $58.9(9.5,37.9-85.3)$ & 0.8 \\
\hline Follow-up time, years & $4.6(1.5,2.4-7.8)$ & $4.4(1.7,2.0-7.8)$ & 0.69 \\
\hline Gender & & & 0.09 \\
\hline Male & $14(34.1)$ & $61(49.6)$ & \\
\hline Female & $27(65.9)$ & $62(50.4)$ & \\
\hline Surgical approach & & & 0.79 \\
\hline Posterior & $21(51.2)$ & $68(55.3)$ & \\
\hline Direct lateral (Hardinge) & $20(48.8)$ & $55(44.7)$ & \\
\hline Operation side & & & 0.13 \\
\hline Left & $24(58.5)$ & $55(44.7)$ & \\
\hline Right & $17(41.5)$ & $68(55.3)$ & \\
\hline Diagnosis & & & 0.08 \\
\hline Primary osteoarthritis & $29(70.7)$ & $97(78.9)$ & \\
\hline Developmental dysplasia of the hip & $4(9.8)$ & $8(6.5)$ & \\
\hline Fracture (acute or post-traumatic) & $4(9.8)$ & $4(3.3)$ & \\
\hline Rheumatoid arthritis & $2(4.9)$ & $6(4.9)$ & \\
\hline Avascular necrosis & $2(4.9)$ & $6(4.9)$ & \\
\hline Other & $0(0.0)$ & $2(1.6)$ & \\
\hline \multicolumn{4}{|l|}{ Diseases affecting bone quality } \\
\hline None & $37(90.2)$ & $104(84.6)$ & 0.39 \\
\hline Rheumatoid arthritis & $2(4.9)$ & $11(8.9)$ & \\
\hline Osteoporosis & $1(2.4)$ & $5(4.1)$ & \\
\hline Alcohol abuse & 0 & $3(2.4)$ & \\
\hline Long-term corticosteroid medication & $1(2.4)$ & 0 & \\
\hline THA type & & & 0.96 \\
\hline Conventional THA & $30(73.2)$ & $30(73.2)$ & \\
\hline Head diameter $\geq 38 \mathrm{~mm}$ & $28(68.3)$ & $82(66.7)$ & \\
\hline Head diameter $<38 \mathrm{~mm}$ & $2(4.9)$ & $8(6.5)$ & \\
\hline HRA & $11(26.8)$ & $33(26.8)$ & \\
\hline Femoral implant type & & & 0.92 \\
\hline Tapered & $6(14.6)$ & $15(12.2)$ & \\
\hline Fit and fill & $24(58.5)$ & $75(61.0)$ & \\
\hline HRA & $11(26.8)$ & $33(26.8)$ & \\
\hline Intraoperative complication & & & 0.01 \\
\hline None & $39(95.1)$ & $115(93.5)$ & \\
\hline Periprosthetic fracture & $1(2.4)$ & $6(4.9)$ & \\
\hline Nerve damage & $1(2.4)$ & $2(1.6)$ & \\
\hline
\end{tabular}

Values are given as mean (SD, range) or $\mathrm{n}(\%)$ as appropriate
It has been suggested that HRA may have better functional outcomes than THA but it also has a higher risk of aseptic loosening and revision [24]. In our study there were more patients with acetabular component loosening in the HRA group compared to the THA group. Age and gender may also be important prognostic factors for the failure of HRA compared to conventional THA [6]. Previously it has been shown that press-fit of the acetabular component was less frequently achieved in females and patients with type $\mathrm{A}$ or $\mathrm{C}$ acetabulum compared to type B [2]. Our findings were similar as there were more acetabulum Dorr type A and C acetabula in the loosening group.

DDH includes a wide spectrum of hip abnormalities. In our study, radiographic analysis found no major DDHs in the acetabular component loosening group. Thus, it seems that DDH may not predispose to early aseptic loosening.

Previous studies suggest that cementless acetabular components migrate during the immediate early post-operative 
Table 2 Radiographic assessments

\begin{tabular}{|c|c|c|c|}
\hline Measure & $\begin{array}{l}\text { Acetabular component } \\
\text { loosening group }\end{array}$ & Control group & $P$-value \\
\hline \multicolumn{4}{|l|}{ Preoperative radiographic measurements } \\
\hline Center-edge angle (CE), ${ }^{\circ}$ & $40.1(16.4,10.0-82.6)$ & $41.2(11.8,4.7-72.0)$ & 0.7 \\
\hline Sharp angle, ${ }^{\circ}$ & $39.8(7.5,23.0-56.6)$ & $38.9(5.1,24.0-55.0)$ & 0.46 \\
\hline Acetabulum inclination, ${ }^{\circ}$ & $53.4(5.7,37.0-64.0)$ & $50.2(4.7,37.0-64.0)$ & 0.001 \\
\hline Acetabulum anteversion, ${ }^{\circ}$ & $23.8(6.0,11.0-35.0)$ & $19.2(5.3,6.0-36.0)$ & $<0.001$ \\
\hline Neck-shaft angle, ${ }^{\circ}$ & $\begin{array}{l}134.6(6.0,118.5- \\
145.7)\end{array}$ & $134.7(5.5,122.0-153.0)$ & 0.82 \\
\hline Acetabulum depth ratio (ADR) & $0.265(1.0,0.09-0.59)$ & $0.259(0.05,0.10-0.43)$ & 0.71 \\
\hline Femoral head extrusion index (FHEI) & $84.7(10.9,60.0-100.0)$ & $83.1(10.5,54.4-101.9)$ & 0.41 \\
\hline $\begin{array}{l}\text { Hip centre of rotation } \\
\text { (horizontal width), mm }\end{array}$ & $32.1(5.7,19.8-45.0)$ & $32.5(5.9,19.0-50.4)$ & 0.76 \\
\hline Hip centre of rotation (vertical height), mm & $23.7(8.1,11.7-47.7)$ & $21.1(5.3,10.0-40.0)$ & 0.07 \\
\hline Acetabulum bone structure & & & 0.014 \\
\hline Type A & $13(31.7)$ & $28(23.0)$ & \\
\hline Type B & $20(48.8)$ & $93(76.2)$ & \\
\hline Type C & $8(19.5)$ & $1(0.8)$ & \\
\hline Unable to measure & 0 & 1 & \\
\hline Crowe DDH classification & & & 0.32 \\
\hline None & $35(85.4)$ & $114(93.4)$ & \\
\hline Type I & $5(12.2)$ & $6(4.9)$ & \\
\hline Type II & $1(2.4)$ & $2(1.6)$ & \\
\hline Type III & 0 & 0 & \\
\hline Type IV & 0 & 0 & \\
\hline Unable to measure & 0 & 1 & \\
\hline \multicolumn{4}{|l|}{ Postoperative radiographic measurements } \\
\hline Acetabular component inclination, ${ }^{\circ}$ & $56.1(14.4,22.0-88.0)$ & $44.3(7.9,26.0-68.0)$ & $<0.001$ \\
\hline Acetabular component anteversion, ${ }^{\circ}$ & $\begin{array}{l}14.9(20.9,-34.0 \text { to } \\
\quad 60.0)\end{array}$ & $21.8(12.3,-16.0$ to 58.0$)$ & 0.001 \\
\hline $\begin{array}{l}\text { Hip centre of rotation } \\
\text { (horizontal width), mm }\end{array}$ & $29.7(6.1,18.0-40.5)$ & $28.5(5.7,7.2-43.2)$ & 0.25 \\
\hline Hip centre of rotation (vertical height), mm & $26.2(7.8,12.0-48.6)$ & $22.1(4.5,12.6-37.8)$ & 0.001 \\
\hline Mean change of the hip rotation centre, $\mathrm{mm}$ & $0.2(13.2,-27.9$ to 33.3$)$ & $2.9(8.3,-17.4$ to 30.0$)$ & 0.006 \\
\hline Change of the hip rotation centre & & & 0.12 \\
\hline$<10 \mathrm{~mm}$ & $23(65.7)$ & $57(49.1)$ & \\
\hline$\geq 10 \mathrm{~mm}$ & $12(34.3)$ & $59(50.9)$ & \\
\hline Unable to measure & 6 & 7 & \\
\hline Cup containment & & & 0.22 \\
\hline Complete $100 \%$ & $22(62.9)$ & $58(47.2)$ & \\
\hline $90-99 \%$ & $8(22.9)$ & $46(37.4)$ & \\
\hline $75-90 \%$ & $5(14.3)$ & $19(15.4)$ & \\
\hline$<75 \%$ & 0 & 0 & \\
\hline Unable to measure & 6 & 0 & \\
\hline Radiolucent lines & & & 0.84 \\
\hline None & $33(94.3)$ & $115(93.5)$ & \\
\hline Yes & $2(5.7)$ & $8(6.5)$ & \\
\hline Unable to measure & 6 & 0 & \\
\hline
\end{tabular}

Values are given as mean (SD, range) or $\mathrm{n}(\%)$ as appropriate period $[25,26]$. After a few months, the rate of acetabular component migration slows down, the component stabilizes and bone impaction finally reaches subsequent osseointegration [27]. Acetabular component migration at 
two years may predict later aseptic loosening of the acetabular component [26]. It is likely that osseointegration never occurred in these patients or was insufficient, leading to subsequent loosening due to increased torque caused by the large diameter femoral head. Lack of initial fixation of the acetabular component results in increased migration and finally manifests with gross loosening of the implant [26]. We found out that the majority of aseptic acetabulum component loosenings occur within two years after the primary arthroplasty. Partial containment of the acetabular component has been associated with a higher incidence of acetabular loosening [28]. However, we were not able to confirm this finding in our study.

The inclination angle of the acetabular component may be related to implant failure due to suboptimal implant positioning and possible impingement. A vertical cup with an inclination angle of more than 50 degrees has been reported to be the most important factor related to aseptic loosening [2]. Our findings support this, as the loosened components were more vertical and less anteverted as compared to controls. CarciaRey et al. also noted that change in the rotation centre of the hip by more than $3 \mathrm{~mm}$ was associated with a higher rate of screw usage in the acetabular component and they suggest that this was a sign of inadequate press-fit of the acetabular component [2]. In our study, the hip rotation centre was changed more often in the control group than in the acetabular component loosening group. However, the mean change of the hip rotation center was minor in both groups $(<3 \mathrm{~mm})$ and it does not have clinical significance. It should also be taken into an account that in dysplastic hips one goal is to place the hip centre of rotation to its normal anatomical location.

The retrospective study design has some inherent limitations, which might be minimized by a prospective study design. However, as early loosening of a hemispherical component was shown to be relatively uncommon, conducting a prospective study would not be feasible. We analyzed the THAs and HRAs together as a single group due to limited sample size (11 in HRA and 30 in THA). We think that pooling the THAs and HRAs is justified, as all the acetabulum components were similar type uncemented hemispherical cups with monoblock design. An important limitation of this study design is the reliance on data provided by the medical and surgical charts. Since patient data is not always properly documented, some of the co-morbidities affecting bone quality may be under-reported. Prior diagnosis of osteoporosis might not always be documented in patient medical records and its precise incidence should be evaluated before index surgery by bone densitometry. We did not stratify the operating surgeons nor their previous experience on performing hip replacement surgeries, as this would be affected by different case mix. The strengths of this study are the large patient cohort, an extensive array of evaluated potential radiological risk factors and that the patient population was collected from three hospitals. This multicentre approach should increase the generalizability of the results.

In conclusion, a cementless hemispherical acetabular component stabilizes during the early post-operative months. However, in one percent of the patients adequate component stabilization is not achieved and osseointegration fails. Based on the results of the present study, acetabular morphology and cup positioning seem to have a significant impact on the risk for early loosening of cementless monoblock acetabular component. Age, gender, operative diagnosis, diseases affecting bone quality, presence of hip dysplasia or acetabular component type did not predict early loosening. The risk for early failure could be lowered by optimal cup positioning during primary implantation and if there is uncertainty about the initial press-fit of the monoblock component, modular acetabular components with screws or cemented acetabular components should be used, especially in Dorr type A and C acetabula.

\section{Compliance with ethical standards}

Funding This study was funded by the Finnish Arthroplasty Society, Finnish Research Foundation for Orthopaedics and Traumatology, Research Foundation of Kuopio University Hospital, the Jane and Aatos Erkko Foundation, Finnish Cultural Foundation, North Savo Regional Fund, and The Finnish Medical Foundation Duodecim.

Conflict of interest and funding The authors state there are no conflicts of interest.

\section{References}

1. Krantz N, Miletic B, Migaud H, Girard J (2012) Hip resurfacing in patients under thirty years old: an attractive option for young and active patients. Int Orthop 36:1789-1794

2. Carcia-Rey E, Carcia-Cimbrelo E, Cruz-Pardos A (2012) Cup press fit in uncemented THA depends on sex, acetabular shape, and surgical technique. Clin Orthop Relat Res 470:3014-3023

3. Fadi D, Levine B, Paprosky W, Della Valle C, Sporer S, Klein G, Levine H, Hartzband M (2012) Metal-on-metal total hip arthroplasty: causes and high incidence of early failure. Orthopedics 35:e1009-e1016

4. Dorr LD, Bechtol CO, Watkins RG, Wan Z (2000) Radiographic anatomic structure of the arthritic acetabulum and its influence on total hip arthroplasty. J Arthroplasty 15:890-900

5. Pakvis D, van Hellemondt G, de Visser E, Jacobs W, Spruit M (2011) Is there evidence for a superior method of socket fixation in hip arthroplasty? A systematic review. Int Orthop 35:1109-1118

6. McBryde $\mathrm{CW}$, Theivendran $\mathrm{K}$, Thomas AMC, Treacy RBC, Pynsent PB (2010) The influence of head size and sex on the outcome of Birmingham hip resurfacing. J Bone Joint Surg Am 92A: $105-112$

7. Bicanic G, Delimar D, Delimar M, Pecina M (2009) Influence of the acetabular cup position on hip load during arthroplasty in hip dysplasia. Int Orthop 33:397-402

8. Schofer MD, Pressel T, Heyse T, Schmitt J, Boudriot U (2010) Radiological determination of the anatomic hip centre from pelvic landmarks. Acta Orthop Belgica 76:479-485 
9. Crowe JF, Mani VJ, Ranawat CS (1979) Total hip replacement in congenital dislocation and dysplasia of the hip. J Bone Joint Surg Am 61A:15-23

10. Wiberg G (1939) Studies on dysplastic acetabula and congenital subluxation of the hip joint with special reference to the complication of osteoarthritis. Acta Chir Scand 83:7-135

11. Sharp IK (1961) Acetabular dysplasia. The acetabular angle. J Bone Joint Surg (Br) 43-B:268-272

12. Cooperman DR, Wallensten R, Stulberg SD (1983) Acetabular dysplasia in the adult. Clin Orthop Relat Res 175:79-85

13. Heyman CH, Herndon CH (1950) Legg-Perthes disease; a method for the measurement of the roentgenographic result. J Bone Joint Surg Am 32A:767-778

14. Fessy MH, N'diaye A, Carret JP, Fischer LP (1999) Locating the center of rotation of the hip. Surg Radiol Anat 21:247-250

15. Widmer KH (2004) A simplified method to determine acetabular cup anteversion from plain radiographs. J Arthroplasty 19:387-390

16. Murray DW (1993) The definition and measurement of acetabular orientation. J Bone Joint Surg (Br) 75B:228-232

17. Craiovan B, Renkawitz T, Weber M, Grifka J, Nolte L, Zhneg G (2014) Is the acetabular cup orientation after total hip arthroplasty on a two dimension of three dimension model accurate? Int Orthop 38:2009-2015

18. Sarmiento A, Ebramzadeh E, Gogan WJ, McKellop HA (1990) Cup containment and orientation in cemented total hip arthroplasties. J Bone Joint Surg (Br) 72-B:996-1002

19. DeLee JG, Charnley J (1976) Radiological demarcation of cemented sockets in total hip replacement. Clin Orthop Relat Res 121:20-32

20. Mäkelä KT, Matilainen M, Pulkkinen P, Fenstad AM, Havelin L, Engesaeter L, Furnes O, Pedersen AB, Overgaarg S,
Kärrholm J, Malchau H, Garellick G, Ranstam J, Eskelinen A (2014) Failure rate of cemented and uncemented total hip replacements: register study of combined Nordic database of four nations. BMJ 348:f7592

21. Lee PY, Rachala M, Teoh KH, Woodnutt DJ (2016) Longterm results with Atlas IIIp elastic cementless acetabular component in total hip replacement. Int Orthop. 2016 Jan 12 [Epub ahead of print]

22. Volkmann R, Schneider MA, Bretschneider C, Weise K (1999) More failures of uncemented acetabular screw-rings than of cemented polyethylene cups in total hip arthroplasties. Int Orthop 23:138-139

23. Ni SH, Guo L, Jiang TL, Zhao J, Zhao YG (2014) Press-fit cementless acetabular fixation with and without screws. Int Orthop 38:7-12

24. Smith TO, Nichols R, Donell ST, Hing CB (2010) The clinical and radiological outcomes of hip resurfacing versus total hip arthroplasty: a meta-analysis and systematic review. Arch Orthop 81:684-695

25. Stocks GW, Freeman MA, Evans SJ (1995) Acetabular cup migration. Prediction of aseptic loosening. J Bone Joint Surg (Br) 77-B: 853-861

26. Stihsen C, Rath C, Radl R, Saalabian AA, Materna W, Rehak P, Windhaer R (2013) Early migration characteristics of a $180^{\circ}$ porous-coated cups with 1-mm press fit. Arch Orthop Trauma Surg 133:707-712

27. Mjoberg B (1991) Fixation and loosening of hip prostheses. Rev Acta Orthop Scand 62:500-508

28. Pellici PM, Salvati EA, Robinson HJ (1979) Mechanical failures in total hip replacement requiring reoperation. J Bone Joint Surg Am 61-A:28-36 